\title{
Os desafios na pesquisa biográfica: de Antonio Carlos Pacheco e Silva à constituição de uma época
}

\author{
The challenges in biographical research: from Antonio Carlos \\ Pacheco e Silva to the constitution of an era
}

\author{
Los desafíos de la investigación biográfica: de Antonio Carlos \\ Pacheco e Silva a la constitución de una época
}

PSIQUIATRIA E POLÍTICA: O JALECO, A FARDA E O PALETÓ DE ANTONIO CARLOS PACHECO E SILVA. Tarelow GQ. Rio de Janeiro: Editora Fiocruz; 2020. 293 p. (Coleção Histórias e Saúde). ISBN: 978-65-5708-005-4.

doi: 10.1590/0102-311X00090221

Os desafios de se trabalhar no campo biográfico são muitos. O que queremos ao escolher uma vida para contar? Que caminhos seguir e que decisões tomar sobre um personagem que escolhemos desdobrar nas páginas de uma narrativa? Didier Eribon, na biografia sobre Foucault, nos diz que: "contar a história de uma vida é uma tarefa praticamente interminável" 1 (p. 14). Muitos trabalhos nesse gênero, como as biografias de Lima Barreto 2 e de Marighella 3, têm sido produzidos de forma exemplar, revelando quão potente é esse tipo de pesquisa e escrita para o debate e problematização de temas fundamentais em nossa sociedade.

O livro do historiador Gustavo Querodia Tarelow, Psiquiatria e Política: o Jaleco, a Farda e o Paletó de Antonio Carlos Pacheco e Silva, é um excelente trabalho que mostra como uma pesquisa biográfica pode ser reveladora de um cenário institucional, político e social de determinado período da vida brasileira. O livro, produto de sua tese de doutoramento na Faculdade de Medicina da Universidade de São Paulo, traz à cena Antonio Carlos Pacheco e Silva, nome funda- mental para entendermos da formação do pensamento psiquiátrico no Brasil e como este se vinculou a toda uma perspectiva de construção da lógica manicomial, excludente e eugênica, influenciando o pensamento de uma época, não ficando apenas retido entre os muros hospitalares.

Logo na abertura de seu trabalho, o autor expõe o caminho que irá tomar na construção e explanação de sua pesquisa biográfica para revelar quem foi Pacheco e Silva ou, melhor dizendo, "não o, mas um Antonio Carlos Pacheco e Silva" 4 (p. 16). Sabe que tem pela frente o desafio de estar biografando um personagem complexo, com muitas ligações profissionais e políticas e, principalmente, transitando e vivendo nas contradições da São Paulo do início do século XX, cenário de grandes embates políticos, econômicos e sociais. Assim, sua opção de trabalho traz uma narrativa extremamente interessante, pois não toma o caminho de fazer uma espécie de grandes vultos da história e muito menos coloca Pacheco e Silva no banco dos réus para julgá-lo por suas ligações com o eugenismo ou práticas políticas.

$\mathrm{O}$ autor conta a vida de seu biografado afirmando sua singularidade, num jogo narrativo que ora o evidencia em seu funcionamento subjetivo, familiar, profissional, ora o faz sumir para trazer para a cena principal o andamento sócio-histórico de uma época que também, durante muitas páginas, é a personagem central do livro. Contudo em nenhum momento perde-se de vista o médico, o político e o empresário Pacheco e Silva. Como dirá Tarelow 4 (p. 23), “o que nos interessa 
aqui são as ferramentas que chamam a atenção para $o$ individual e particular - o micro - em constante relação com o seu contexto histórico - o macro”. Assim, o livro não só interessa pela temática, mas traça uma boa discussão para quem tem, nos trabalhos biográficos, uma estratégia de pesquisa e o desejo de enveredar em um mundo caleidoscópico ${ }^{5}$.

Decisão interessante no livro foi dividi-lo em eras, tomando emprestada, dos trabalhos e escritos de Eric Hobsbawm, esta perspectiva. Com isso, Tarelow foge de uma cronologia linear do fato após fato, conseguindo organizar a dimensão temporal de sua narrativa entre o que foi vivido por Pacheco e Silva em sua trajetória e os efeitos e impactos dessa caminhada no próprio andamento histórico do mundo no século XX. Então, o autor escreve sobre uma Era Formativa, o início, a família e a chegada à Psiquiatria; uma Era do Fulgor, a ascensão profissional e como foi se criando o influente e prestigiado Pacheco e Silva; e, ao findar o livro, a Era dos Acirramentos, que podemos entender como o modo como Antonio Carlos Pacheco e Silva viveu as últimas décadas da sua vida, ainda circulando e flertando com instâncias de poder. Toda essa opção para sua narrativa histórica faz que o autor crie um livro que foge da monotonia cronológica biográfica, pois organiza os acontecimentos dentro de um panorama que permite um cruzamento dos dados propriamente biográficos com a vasta pesquisa documental e teórica. Ou seja, metodologicamente falando, o livro cumpre seu roteiro de trabalho e apresenta um estudo biográfico no qual Pacheco e Silva é revelado naquela perspectiva que o autor se propôs a trabalhar.

Tomando outra linha de análise, o livro de Tarelow nos permite abrir mais uma trilha de conhecimento neste vasto campo que é a história da psiquiatria e da doença mental no Brasil. Ao escrever sobre Pacheco e Silva, o autor nos apresenta de que modo foi se forjando um pensamento manicomial que, ao praticar as tecnologias médicas francesas e alemãs e aplicá-las no Brasil, autorizou-se a "desenvolver testes em indivíduos (em geral pobres é importantes que se ressalte) sob a custódia da medicina psiquiátrica em nome do avanço das ciências" 4 (p. 105). Tudo isso vivido em parte dentro do Hospital do Juquery e outros grandes manicômios surgidos e construídos nessa época, a exemplo do que ocorria na Europa. Vale res- saltar que o livro não perde, em sua narrativa, uma perspectiva que podemos perceber através da trajetória da vida de Pacheco e Silva, como foi se articulando certa noção de doença mental totalmente cruzada com a construção de um pensamento eugenista no Brasil do século XX. Esse fato legitimava uma divisão da sociedade entre aqueles que seriam considerados dignos de viver e usufruir das dinâmicas da vida social, incluindo aí a própria circulação pelas cidades em crescimento naquele momento e os outros que deveriam ser banidos, isolados, excessivamente controlados e colocados sob suspeitas. Disso resultava que "todos os problemas sociais tinham origem na presença de elementos inferiores na formação racial brasileira" 4 (p. 117). Lendo o livro, percebemos o quanto essas ideias foram formadoras de uma mentalidade social e cultural ainda hoje presentes em nosso território e que ganham força nos discursos racistas que envolvem os mais diversos aspectos da sociedade.

Desse modo, o trabalho do historiador Tarelow não é somente a biografia de Antonio Pacheco e Silva e a história sobre como esse personagem criou serviços, instituições, formou uma legião de outros psiquiatras, conviveu com nomes como Franco da Rocha, Henrique Belford Roxo, Durval Marcondes e caminhou até a presidência da Federação Mundial para a Saúde Mental. O livro nos mostra como, por meio da condução biográfica de Pacheco e Silva, podemos ampliar e observar a construção de argumentos, lógicas e dispositivos (sejam psiquiátricos ou educacionais) que foram reguladores de uma parcela da vida da nação e de sua população, pois sabemos que, durante muito tempo, usamos da teoria eugenista e de teorias raciais para justificar, por exemplo, a questão do fracasso escolar em crianças negras e pobres no Brasil 6. Apesar de o livro não operar esse deslocamento, fica claro quando estudamos a história da educação no Brasil e de certas concepções de desenvolvimento infantojuvenil, como o texto de Tarelow nos dá o cenário cultural, social e político no qual houve a gestão dessas ideias em solo brasileiro e como influenciaram certas linhas de comando institucional: como escolas, políticas de habitação e, claro, o próprio campo da assistência psiquiátrica.

Caminhando para o final de seu trabalho, Era dos Acirramentos, o autor nos apresenta um $\mathrm{Pa}$ - 
checo e Silva e sua entrada na luta anticomunista, e sua presença marcante no cenário das Forças Armadas. Biograficamente, é interessante perceber como a trajetória desse médico psiquiatra e suas convicções o colocaram em consonância com o golpe militar de 1964 e à produção de textos de pensamento e engajamento anticomunista, como sua monografia na Escola Superior de Guerra: A Guerra Subversiva em Marcha ${ }^{4}$. Para Tarelow, Pacheco e Silva foi cada vez mais participando, apaixonadamente, desse acirramento entre as diversas posições políticas desse período. O fato de essa biografia ter ido tão longe na vida de Antonio Carlos Pacheco e Silva nos permitiu observar o quanto, no desdobramento de sua vida, há uma coerência entre o que ele pensou em termos médicos, sociais, biológicos e sua presença no cenário do golpe de 1964 e suas posições ideológicas. Nesse sentido, o caminho escolhido pelo historiador para a construção de seu personagem vai se tornado mais interessante, já que, ao final do trabalho, sua narrativa não esfria e mantém a visão complexa de Pacheco e Silva.

Por tudo isso, o livro se revela um excelente material de estudo no campo da história da Psiquiatria, Medicina e Psicologia ou, simplesmente, um texto que vai interessar pelo que traz de estudo sobre os vários debates importantes da história política brasileira.

\section{Marcelo de Abreu Maciel 1}

1 Universidade Federal Fluminense, Rio das Ostras, Brasil. mdabreu@uol.com.br

\section{Informação adicional}

ORCID: Marcelo de Abreu Maciel (0000-00022791-0456).

1. Eribon D. Foucault. São Paulo: Companhia das Letras; 1990.

2. Schwarcz LM. Lima Barreto. Triste visionário. São Paulo: Companhia das Letras; 2017.

3. Magalhães M. Marighella: o guerrilheiro que incendiou o mundo. São Paulo: Companhia das Letras; 2012.

4. Tarelow GQ. Psiquiatria e política: o jaleco, a farda e o paletó de Antonio Carlos Pacheco e Silva. Rio de Janeiro: Editora Fiocruz; 2020.

5. Motta A. Prefácio. In: Tarelow GQ. Psiquiatria e política: o jaleco, a farda e o paletó de Antonio Carlos Pacheco e Silva. Rio de Janeiro: Editora Fiocruz; 2020. p. 12.

6. Patto MHS. A produção do fracasso escolar: histórias de submissão e rebeldia. São Paulo: Editora Intermeios; 2015. 